\title{
What are the highly important and desirable patient engagement actions for self-care as perceived by individuals living in the southern United States?
}

\author{
This article was published in the following Dove Press journal: \\ Patient Preference and Adherence \\ 31 January 2017 \\ Number of times this article has been viewed
}

\author{
Huey-Ming Tzeng' \\ James Marcus Pierson ${ }^{2}$ \\ 'Whitson-Hester School of Nursing, \\ Tennessee Technological University, \\ Cookeville, TN, ${ }^{2}$ Cambridge \\ Management Group, Belmont, \\ MA, USA
}

Aim: This exploratory survey study aimed to identify patient engagement actions that are the most frequently named as being highly important (top 30 by importance) or ones that they want to do (top 30 by desire) for community-dwelling adult patients living in the southern United States. Items not making the list of the top 30 by ability were also identified.

Background: Patient engagement is still an ambiguous term among population health and health care professionals in the United States as we lack a clear understanding of what it entails.

Methods: This 2015-2016 study used convenience sampling to recruit subjects in a university's student health service department and in eight senior centers. Two hundred and fifty adult patients older than 18 years in the Upper Cumberland region of Tennessee participated in the study ( $82 \%$ response rate). A 57 -item inventory, "The Patient Action Inventory for Self-Care," was developed and used to ascertain patients' self-designated preferences and capabilities in order to understand their needs for education and support.

Results: Respondents included 159 (63.6\%) women, 62 (24.8\%) men, and 29 (11.6\%) who did not indicate their gender. Combining the list of the top 30 importance items and the list of the top 30 desired items yielded a list of 35 items; noteworthy is the fact that the list of the top 30 ability actions contained nine items that were not found in a previously mentioned list of 35 high-ranking importance and desired items. This study validated the necessity of analyzing patient engagement actions by importance, desirability, and ability to accomplish it. These three levels are distinct from each other.

Conclusion: Nurses may use future versions of the inventory to assist patients in identifying self-care actions to engage in. Use of the inventory will demonstrate respect for patients' preferences and may thus improve engagement.

Keywords: nurse, nursing, patient participation, self-care, patient engagement, patient involvement

\section{Introduction}

Patient engagement is defined as a set of actions that patients or community-dwelling residents use to support their health, which allow them to benefit from health care services. ${ }^{1}$ In this study, our focus is on community-dwelling individuals living in the southern United States, and the term "patients" is used referring to seniors and college students who may be well and may not have a medical condition. A populationbased, cross-sectional survey of 4,343 subjects aged 40 years or older with chronic obstructive pulmonary disease (COPD) in 12 countries, conducted by Müllerová et $\mathrm{al}^{2}$
Correspondence: Huey-Ming Tzeng Whitson-Hester School of Nursing, Tennessee Technological University, Cookeville, I0 W. 7th Street, Cookeville, TN 38505-000I, USA

$\mathrm{Tel}+\mathrm{I} 7343580358$

Email tzenghm@gmail.com 
in 2016, revealed that low patient engagement (measured by the 13-item Patient Activation Measure) and poor medication adherence (measured by the eight-item Morisky Medication Adherence Scale) are associated with poor COPD-specific health status, high health care utilization, and low satisfaction with health care providers. In the United States, in 2015, Pittman and Forrest ${ }^{3}$ also found that patient engagement is key for containing medical care costs. Significantly, in 2014, the Center for Advancing Health (CFAH $)^{4}$ claimed that patient engagement is still an ambiguous term among population health and health care professionals in the United States due to a lack of understanding regarding what actions patient engagement entails.

\section{Background}

Literature searches using the term "patient engagement" in PubMed in September 2014 and May 2016 failed to identify any comprehensive checklist or inventory of desired patient engagement actions or behaviors for self-care (other than CFAH). ${ }^{4}$ Our searches and research were performed with the assumption that such a instrument could help individual patients to gain a better understanding of what actions they or their lay caregivers need to take for them to benefit from the available health care delivery system.

Two instruments were identified as relevant to the present study. The Patient Activation Measure developed by Hibbard et $\mathrm{al}^{5}$ in 2005 is an interval-level, unidimensional measure of the active role of patients in their self-care. This instrument contains 13 items using a four-point scale. This measure assesses patients' knowledge, skill, and confidence for selfmanagement related to their chronic conditions. The Patient Activation Measure focused on physical conditions and was designed to measure the construct of activation. ${ }^{5}$ Based on the patient health engagement model, in 2015, Graffigna et $\mathrm{al}^{6}$ developed and tested the Patient Health Engagement Scale, which focuses on engagement as a psychosocial construct and intends to measure the engagement stages of patients with chronic illness. This five-item version of the Patient Health Engagement Scale is measured on a seven-point scale. In order to describe patient engagement, Graffigna et $\mathrm{al}^{6}$ in 2015 developed the patient health engagement model, which includes a three-level process with four stages for each level. Patient engagement is conceptualized as a think-feel-act process that involves multidimensional experience related to the cognitive, emotional, and active orientations of patients toward their health management. In this think-feel-act process, patients may exhibit four subsequent engagement stages: blackout, arousal, adhesion, and eudaimonic project.
The 2014 publication of $\mathrm{CFAH}^{4}$ Here to stay: What health care leaders say about patient engagement drew attention to their Engagement Behavior Framework, ${ }^{7}$ which was designed to guide people on what they must do to benefit from available health services. The Engagement Behavior Framework encompasses 52 patient engagement actions grouped into ten categories. One of the purposes to develop this Framework was to assess the size and scope of the challenges patients face to engage in their health and health care. This effort may lead to strategically targeted interventions to support the capacity of patients and their caregivers to engage in patients' health and health care. ${ }^{7}$ More details about the Engagement Behavior Framework will follow.

The CFAH's Engagement Behavior Framework is a qualitative description of the behaviors, which was meant to capture the full range of actions patients in the United States are now expected to do if they are to optimally benefit from the health care delivery systems available to them or their caregivers. ${ }^{7}$ In 2010, CFAH took a major step toward assembling a detailed, comprehensive picture of the implicit and explicit demands posed to individuals by current health care delivery practices in the United States and among vulnerable subgroups. CFAH staff together with six invited experts interviewed 210 patients and caregivers about their experience with health care following a serious diagnosis. The contributors also reviewed the advocacy literature, research topics in the published literature, and relevant systematic reviews. They conducted a total of 57 key informant interviews. After assembling a draft list of 73 behaviors, the Engagement Behavior Framework was constructed by the contributors and reviewed by an external review group consisting of 30 people: 15 physicians and nurses, eight researchers, and seven individuals with no professional connection with health care. The external review group's comments were integrated by a subgroup of the contributors, which resulted in a total of 52 behaviors, which were grouped into ten types of tasks that constitute the Engagement Behavior Framework. ${ }^{7}$ As per CFAH, this 52-behavior Engagement Behavior Framework has not been tested beyond the white paper published in 2010.

With the permission from $\mathrm{CFAH}$, based on the 52 behaviors in the 10-group Engagement Behavior Framework, ${ }^{7}$ the research team (including a linguistic specialist/elementary teacher, two nursing research assistants, a physician researcher/the second author of this article, and a nurse researcher/the first author of this article) paraphrased these 52 behaviors into a 51-item patient action inventory on a sixth grade reading level. This process included shortening the 
description of the 52 behaviors in the Engagement Behavior Framework, paraphrasing multiple-behavior items so that each item includes only one action, and combining similar items into one action. The original 10-group Engagement Behavior Framework structure was kept. After paraphrasing the original behavior statements, the new 51 actions were developed and grouped into ten categories based on each action's corresponding group in the original 10-group Framework (see Table 1 for the first ten categories, items 1-51).

The second author was consulted as a physician with expertise in population health, care coordination, and transition of care. As a result of these discussions, six more items, also described on a sixth-grade reading level (see Table 1 for the 11th category, items 52-57), were added to the list of actions for study. The resulting inventory, a 57-item inventory of patient engagement actions for self-care, was designed jointly by the first and second author. The inventory was developed with the intention of assisting population health and health care professionals in understanding their patients' or clients' needs for patient education and support. It could also potentially prompt individuals to discuss their health needs with health care providers and to obtain support for needed actions. The 51 items based on the Engagement Behavior Framework and the whole inventory (with the additional six items, named as "The Patient Action Inventory for Self-Care") have not previously been studied from the perspective of patients or their caregivers. The whole inventory was used for data collection in this study.

\section{Purpose of this study}

This exploratory survey study was developed to identify highly important and desirable patient engagement actions for self-care as perceived by community-dwelling individuals living in the southern United States. The 57-item patient engagement action inventory for self-care described in the previous section was used in this study. This study was intended to establish face validity of a new survey.

The purpose of this study was to identify a reduced set (30-40) of patient engagement actions from among the 57 actions in the inventory that patients most frequently name as being important (top 30 by importance) or ones they want to do (top 30 by desire). Nine of these selected top importance and desirable actions were not in the top 30 ability actions for self-care. The rationale that the authors chose to identify the top 30 importance, desire, and ability actions was to highlight roughly the top $50 \%$ of the identified 57 actions.

In the present study, we assume that supporting patients' desires for self-care and capability for health system navigation would lead to reduced medical care costs and improving adherent behaviors. The assumptions of this study are as follows: 1) Patient engagement actions marked as being important to self-care could contribute to patients' awareness and knowledge; 2) an action that patients indicate that they want to do could indicate motivation to learn or to perform the action; and 3) an engagement action that a patient perceives being important and expresses desire to perform but being unable to perform (ie, not among the top 30 ability actions) could signal a need for support, help, or patient education. The main research question is as follows: What are the top 30 health care engagement actions for self-care that patients most frequently identify as being important or desirable?

\section{Methods Design}

This exploratory cross-sectional survey study was conducted in a university's health service department and in eight senior centers in the southern United States from September 2015 through May 2016. Two senior centers were located in an urban area, and six were in rural areas. This study was approved by the Institutional Review Board of the Tennessee Technological University, Cookeville, Tennessee.

\section{Sample and procedures}

This project used convenience sampling to recruit subjects, and the participation was voluntary. The participant selection in the present study was broad with a goal to gain an understanding across different adult age groups. This inventory intends to gain insight into patients' experience and perception on each engagement action based on the importance, desire, and ability levels that patients (or their caregivers) face when engaged in their health and health care. The participants may be well and may not have a medical condition. The data collection locations were selected based on proximity to the Tennessee Technological University campus for ease of access. The University is located in the Upper Cumberland region of Tennessee, which includes 14 counties and 15 senior centers.

The targeted sample size for this project was set at 250, which was based upon study resources available. Subjects were community-dwelling adult patients living in the Upper Cumberland region of Tennessee, including the people who visited one of the eight surveyed senior centers and the students and employees at the Tennessee Technological University who visited the student health service during the study period. The targeted sample size was reached through surveying eight senior centers and the student health service at the Tennessee Technological University. 


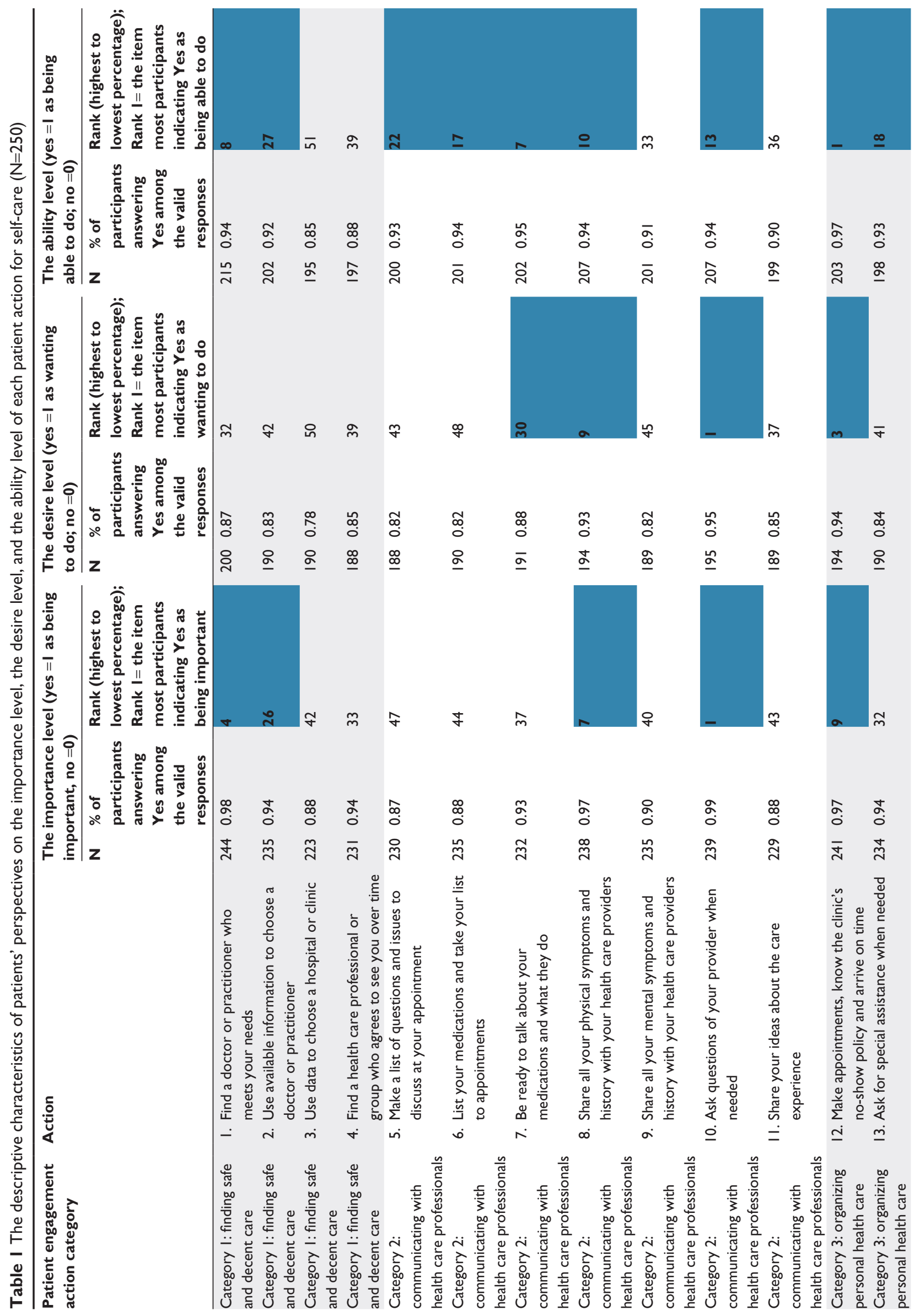



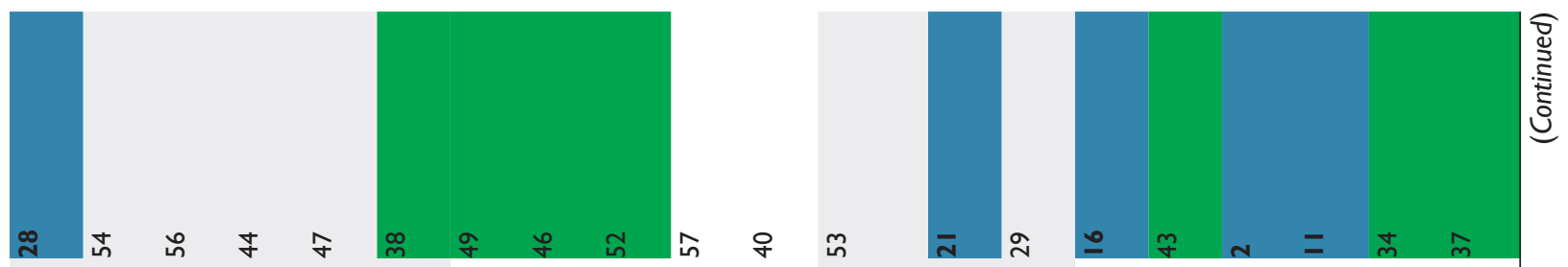

今. ปี
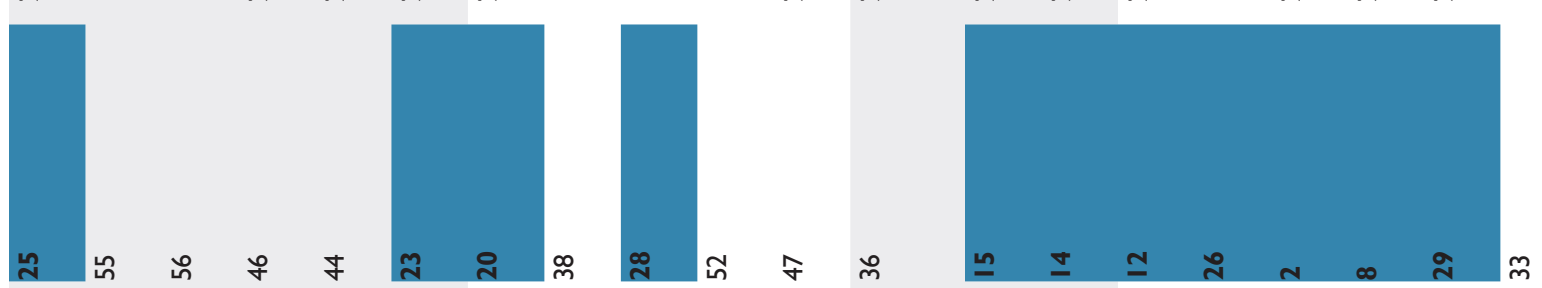

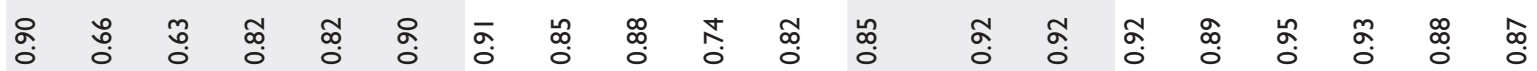

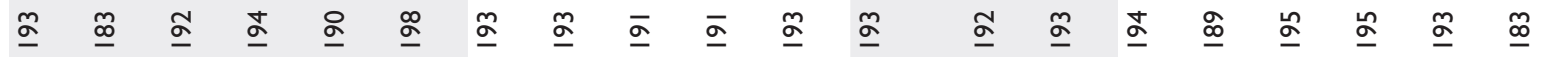
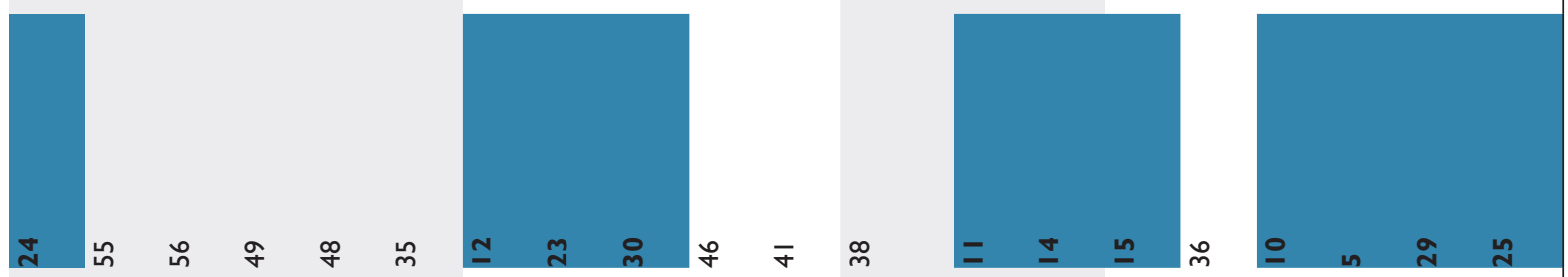

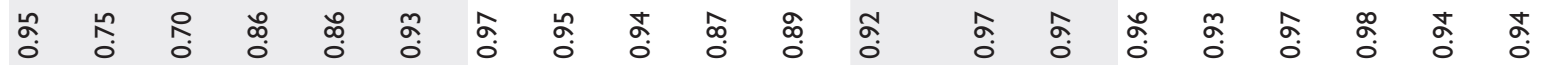
ఫ

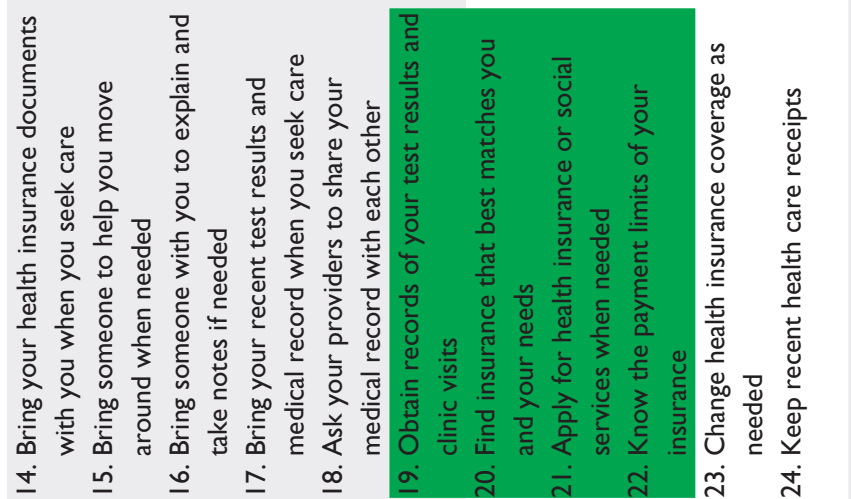
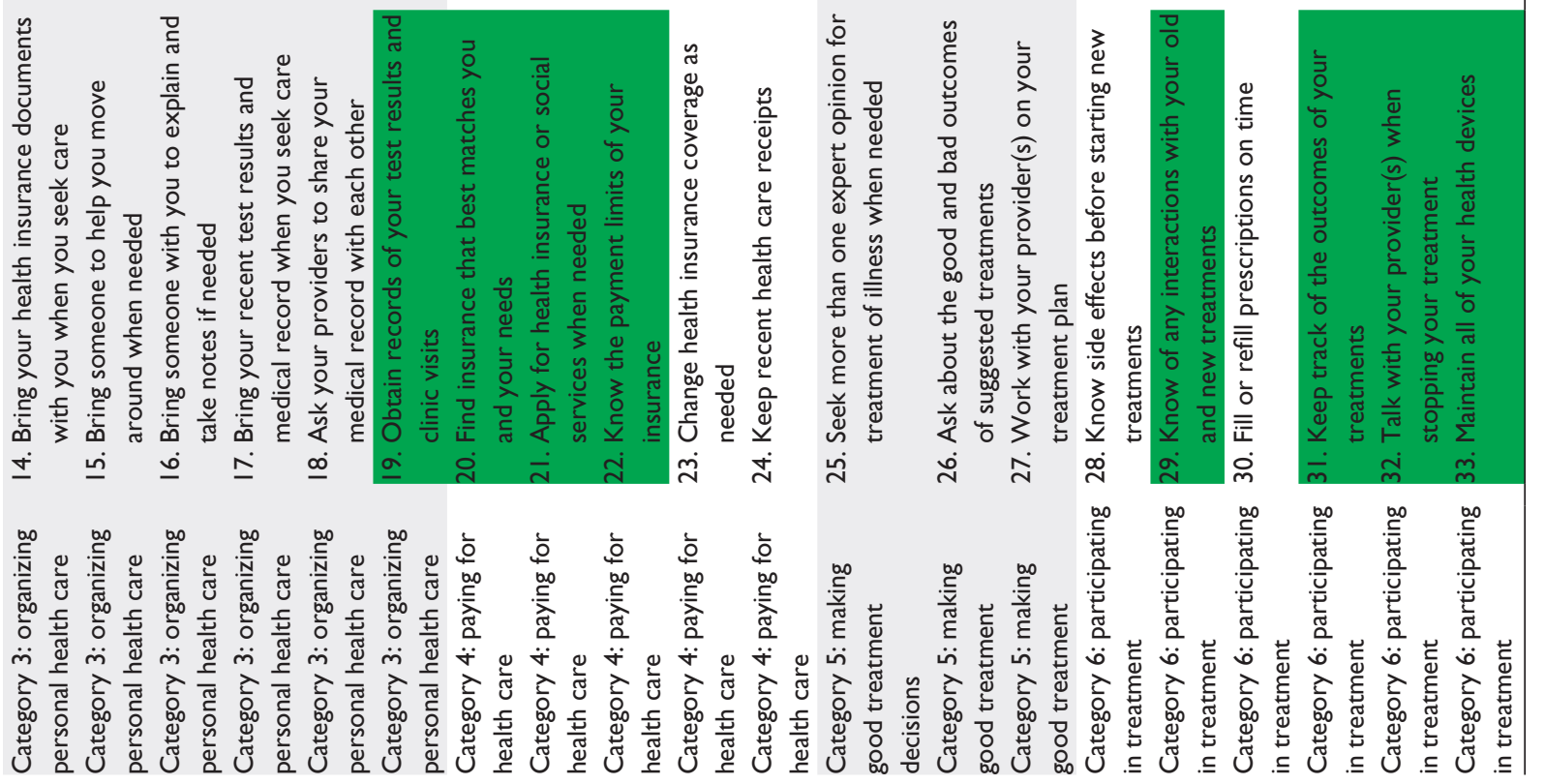

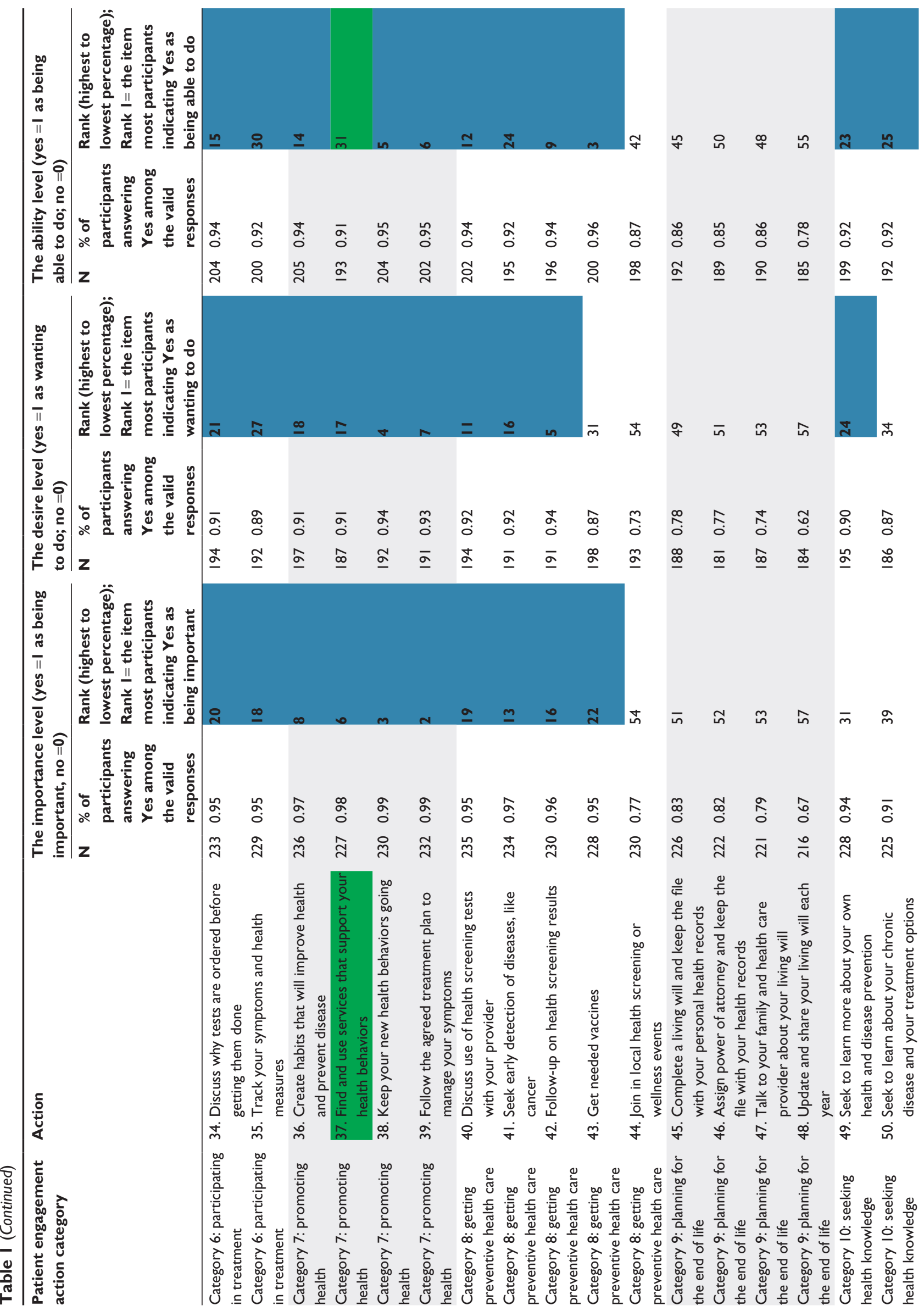

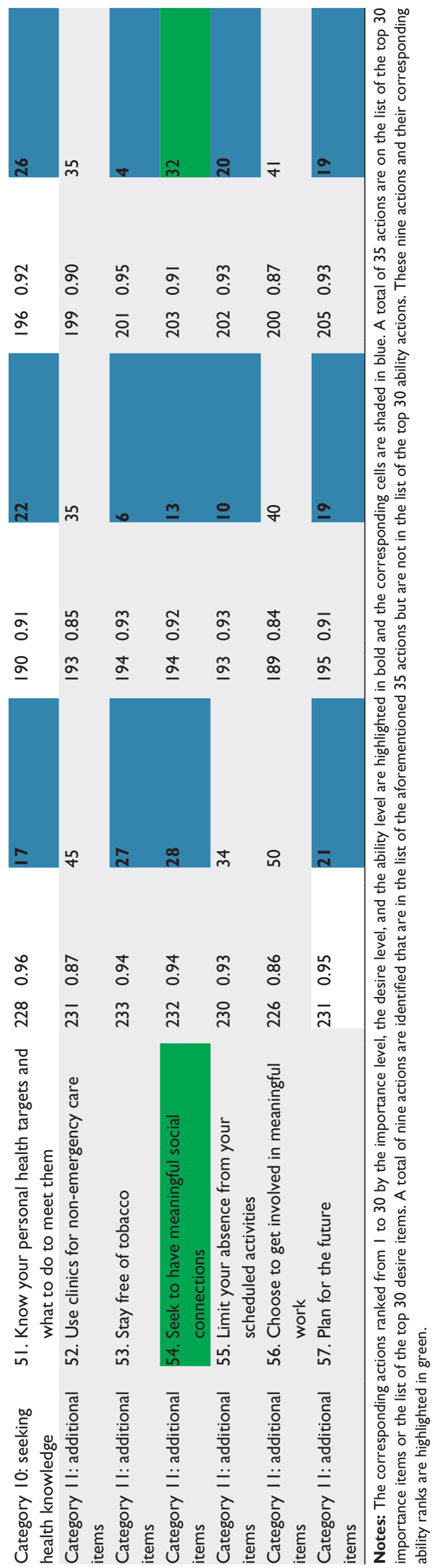

All participants were 18 years or older. Individuals who had taken the survey previously were excluded. Participants answered the survey themselves or on behalf of someone they were providing care for.

Potential participants were approached by trained research assistants at each senior center at times agreed upon between the senior center director and the research team. Each data collection session was announced in the senior center activities program beforehand. Potential participants were also approached by trained research assistants at the student health service department of the corresponding author's university at times agreed upon between the department director and the research team. In both settings, individuals who agreed to participate went to a meeting room where a trained research assistant obtained their written informed consent to participate. The hard copy survey was administered in-person. After completing the survey, each participant received a US $\$ 5.00$ grocery gift card in appreciation.

\section{Instrumentation}

The survey package included four parts: (Part I) "The Patient Action Inventory for Self-Care" (57 items; this inventory is available from the corresponding author by e-mail). Participants were asked to indicate Yes or No for each action statement from three perspectives: 1) Is this important to you? 2) Do you want to do this? 3) Are you able to do this? (Part II) Patient Activation Measure; (Part III) Positive and Negative Affect Schedule; and (Part IV) Demographic and general health questions. Participant identifiers were not recorded or tracked. Participants were permitted to skip items that they did not wish to answer. The survey package took about 40 minutes to complete.

Data collected in Parts I and IV were used for analyses. Only the data collected in Parts I and IV were reported in this article because the focus of this article is on the newly developed "The Patient Action Inventory for Self-Care." The data collected in Part IV were reported to describe the demographic characteristics of the survey participants. Future articles will address the relationship of patient selfcare actions in health care with other constructs (ie, patient activation, and positive and negative affect).

\section{Analyses}

Data were processed using IBM SPSS 23.0 statistical software (International Business Machines Corporation, Armonk, NY, USA). Data from completed or partially completed surveys were included in the analysis, and descriptive analyses were used. For "The Patient Action Inventory for Self-Care," two analyses were conducted: 1) for each 
action item, the mean value to describe the percentage of the participants answered Yes as 1 versus No as 0; and 2) by each of the three perspectives - importance, desirability, and perceived ability. The ranks are indicated from the highest to the lowest percentage, where Rank 1 indicates the item that most participants indicated with Yes. The arithmetic mean was used as a measure of importance, desire, and ability levels for each action item. Selected demographic characteristics are presented using frequencies.

Reliability statistics for the 11 patient engagement action categories (also called scales) and for each of the importance, desire, and ability levels were calculated using Cronbach's alpha based on standardized items. Neither the Engagement Behavior Framework ${ }^{7}$ nor "The Patient Action Inventory for Self-Care" has been tested in a clinical setting. Reliability testing was conducted to check "The Patient Action Inventory for Self-Care" to determine if each of the categories is reliable with the sample used in the present study. The reliability statistics could assist the authors further refining the self-care action items.

\section{Results}

A total of 305 potential subjects who met the inclusion criteria and had not completed the survey previously were approached; 250 completed the surveys partially or entirely. The statistics were calculated without adjusting for missing values. Since the participants may choose to not answer every item, we included all the reported data in the analysis.

Demographics of the study participants are: $65(26 \%)$ surveys were completed in the student health service department, and 185 (74\%) were completed in the senior centers. The response rate was $82 \%$. Five responded to the survey for someone else (ie, the husband of a patient and the paid caregiver of a patient). One hundred fifty-nine (63.6\%) participants were women, $62(24.8 \%)$ were men, and 29 $(11.6 \%)$ did not indicate their gender. Thirty-two $(12.8 \%)$ were 18-20 years old, $24(9.6 \%)$ were $21-24$ years old, six $(2.4 \%)$ were $25-35$ years old, one $(0.4 \%)$ was $35-44$ years old, seven $(2.8 \%)$ were $45-54$ years old, 37 (14.8\%) were 55-64 years old, $60(24.0 \%)$ were 65-74 years old, 45 (18\%) were 75-84 years old, $16(6.4 \%)$ were $85-94$ years old, three $(1.2 \%)$ were 95 years old and older, and 19 (7.6\%) did not indicate their age. Seventy (28\%) were married, $132(52.8 \%)$ were single, $13(5.2 \%)$ were separated, and 35 (14\%) did not answer. Two hundred thirteen $(85.2 \%)$ were White, non-Hispanic; 11 (4.4\%) were White, Hispanic; six (2.4\%) were Black or African American; five (2.0\%) were American Indian or Alaska Native; and three (1.2\%) were Asian.
Two hundred nine $(83.6 \%)$ had a high school diploma or higher degree. Twenty-two (8.8\%) had an emergency room admission at least once in the last three months. Twelve (4.8\%) were hospitalized in the last three months, nine had one hospitalization, and one had two. Two hundred nineteen $(87.6 \%)$ had health insurance, 14 (5.6\%) did not have health insurance and 17 (6.8\%) did not respond.

Table 1 shows the actions and the calculated percentages of participants who indicated that the action was important to them, they wanted to do, and they were able to do. The ranking is by percentage of answers Yes to importance, desire, and ability, respectively. The corresponding actions ranked from 1 to 30 by the importance level, the desire level, and the ability level are highlighted in bold, and the corresponding cells are shaded in blue. A total of 35 actions are on the list, which included all of the top 30 importance items and all of the top 30 desire items.

Among the top 30 importance items or the top 30 desire items, at least one action from each category was listed, with the exception of Category 9: planning for the end of life. Among these nine low-ranking items not in the list of the top 30 ability actions, one (no 19: Obtain records of your test results and clinic visits) was in Category 3: organizing personal health care; three actions (no 20: find insurance that best matches you and your needs; no 21: apply for health insurance or social services when needed; and no 22: know the payment limits of your insurance) were in Category 4: paying for health care; three actions (no 29: know of any interactions with your old and new treatments, no 32: talk with your providers when stopping your treatment, and no 33: maintain all of your health devices) were in Category 6: participating in treatment; one action (no 37: find and use services that support your health behaviors) was in Category 7: promoting health; and one action (no 54: seek to have meaningful social connections) was in Category 11: additional items.

A total of nine actions were identified that are in the list of the aforementioned 35 actions but are not in the list of the top 30 ability actions. These nine actions and their corresponding ability ranks are highlighted in green in Table 1. Among these nine low ranking items, all nine of the low ranking ability items require a locus of control beyond the patient; these patient engagement actions currently require the involvement of the provider, the lab, the insurance industry, or in one case social connectors. Removing these barriers or codependencies could improve self-care.

The reliability statistics by patient engagement action categories using Cronbach's alpha are presented in Table 2. 
Table 2 Reliability statistics: Cronbach's alpha based on standardized items $(\mathrm{N}=250)$

\begin{tabular}{|c|c|c|c|c|}
\hline $\begin{array}{l}\text { Patient engagement action } \\
\text { category }\end{array}$ & $\begin{array}{l}\text { Number } \\
\text { of items }\end{array}$ & $\begin{array}{l}\text { The importance level }(\text { yes }=I \\
\text { as being important, no }=0)\end{array}$ & $\begin{array}{l}\text { The desire level }(\text { yes }=I \\
\text { as wanting to, no }=0)\end{array}$ & $\begin{array}{l}\text { The ability level }(\text { yes }=I \\
\text { as being able to, no }=0)\end{array}$ \\
\hline $\begin{array}{l}\text { Category I: finding safe and decent } \\
\text { care (items I-4) }\end{array}$ & 4 & 0.705 & 0.858 & 0.765 \\
\hline $\begin{array}{l}\text { Category 2: communicating with } \\
\text { health care professionals (items } 5-\text { II) }\end{array}$ & 7 & 0.742 & 0.835 & 0.853 \\
\hline $\begin{array}{l}\text { Category 3: organizing personal health } \\
\text { care (items } 12-19 \text { ) }\end{array}$ & 8 & 0.660 & 0.797 & 0.798 \\
\hline $\begin{array}{l}\text { Category 4: paying for health care } \\
\text { (items 20-24) }\end{array}$ & 5 & 0.717 & 0.797 & 0.843 \\
\hline $\begin{array}{l}\text { Category 5: making good treatment } \\
\text { decisions (items } 25-27 \text { ) }\end{array}$ & 3 & 0.670 & 0.771 & 0.786 \\
\hline $\begin{array}{l}\text { Category 6: participating in treatment } \\
\text { (items 28-35) }\end{array}$ & 8 & 0.791 & 0.932 & 0.899 \\
\hline $\begin{array}{l}\text { Category 7: promoting health } \\
\text { (items } 36-39 \text { ) }\end{array}$ & 4 & 0.770 & 0.900 & 0.817 \\
\hline $\begin{array}{l}\text { Category 8: getting preventive health } \\
\text { care (items } 40-44 \text { ) }\end{array}$ & 5 & 0.628 & 0.783 & 0.756 \\
\hline $\begin{array}{l}\text { Category 9: planning for the end of life } \\
\text { (items 45-48) }\end{array}$ & 4 & 0.901 & 0.898 & 0.893 \\
\hline $\begin{array}{l}\text { Category 10: seeking health } \\
\text { knowledge (items } 49-5 \mathrm{I} \text { ) }\end{array}$ & 3 & 0.665 & 0.785 & 0.811 \\
\hline $\begin{array}{l}\text { Category II: additional items } \\
\text { (items } 52-57 \text { ) }\end{array}$ & 6 & 0.513 & 0.648 & 0.655 \\
\hline The inventory (including all items) & 57 & 0.946 & 0.969 & 0.968 \\
\hline
\end{tabular}

Including all 57 actions, reliability statistics using Cronbach's alpha values were 0.946 for the importance items, 0.969 for the desire items, and 0.968 for the ability items. The Cronbach's alpha coefficients of the following five importance categories were lower than 0.7: Category 3: organizing personal health care $(\alpha=0.660)$, Category 5: making good treatment decisions ( $\alpha=0.670)$, Category 8: getting preventive health care $(\alpha=0.628)$, Category 10: seeking health knowledge ( $\alpha=0.665$ ), and Category 11: additional items $(\alpha=0.513)$. For both the desire and ability levels, Category 11: additional items had a Cronbach's alpha coefficient lower than 0.7 (0.645 and 0.655). These findings implied that the desire and ability scales were relatively more reliable than the importance scales.

\section{Discussion}

This is the first quantitative study that intended to explore the construct of patient engagement actions by testing a newly developed inventory of patient engagement actions. Built upon the Engagement Behavior Framework, " "The Patient Action Inventory for Self-Care" was developed to include a total of 57 actions. These actions were ranked by patients or their caregivers based on each action statement's importance, desire, and ability levels. This action inventory is different from the Patient Activation Measure, ${ }^{5}$ which measures the construct of activation, and the Patient Health Engagement Scale, ${ }^{6}$ which focuses on the construct of engagement. A brief summary of the study findings follows.

We first identified the subset of patient engagement actions from among the 57 actions in the inventory that patients most frequently name as being important (top 30 by importance) and the ones they want to do (top 30 by desire). A total of 35 actions cover top 30 importance items and the top 30 desire items. This process reduced the 57-item set of actions to 35 higher priority actions. Please note that nine actions in this list are not found in the top 30 ability actions.

The findings of this study demonstrate the usefulness of analyzing patient engagement actions via patients' viewpoints, in particular from the perspectives of each action's importance and their desire and ability to accomplish it. These three levels are distinct from each other. If the content of all items perceived as being both important and desired can be performed, such coherence could imply that the health care system meets our patients' needs for selfcare. When patients are unable to perform the content of the items that are both important and desired among the top 30 actions, this could suggest that a gap or deficiency exists and more education and/or support to patients and their lay caregivers (eg, family caregivers) is warranted. The three perspectives of importance, desire, and ability in the newly 
developed inventory are similar to the think-feel-act process in the patient health engagement model developed by Graffigna et al. ${ }^{6}$

\section{Conclusions and applications for nursing practice}

This study investigates patient engagement actions for selfcare from the three patient perspectives across ten domains. It is concluded that "The Patient Action Inventory for SelfCare" appears to have face validity in the population studied. However, the inventory still needs further evaluation of practical usefulness.

As for the limitations of this study, the generalizability of the findings to wider populations (eg, younger adults, different geographic characteristics) and the populations with specific chronic or acute illness or ethnic groups is limited, as this study used a convenience sample (eg, total southern US population demographics, $49.6 \%$ of the participants 65 years or older). The distribution of patient engagement actions and their importance, desire, and ability levels perceived by patients may vary with demographic factors. At present, the whole survey package takes about 40 minutes to administer. The present version of "The Patient Action Inventory for Self-Care" alone takes about 25-30 minutes to complete; this could be a barrier for using in practice.

Speculations on the importance and implications of these findings for patients and clinical practice follow. Esposito et $\mathrm{al}^{8}$ argued that patient engagement should be a nursesensitive indicator, as nurses could play a pivotal role in motivating and supporting patients to be engaged in their care and achieve their health and wellness goals. A patientreported measure of self-care ability is needed. Within their practice, nurses may use a future reduced set version of "The Patient Action Inventory for Self-Care" to help patients identify and focus on engagement actions that are important to them. Use of this inventory demonstrates respect for a patient's personal preferences and may thus improve engagement. A version of this inventory could possibly be used in various health and medical care settings across the care continuum to identify the most relevant patient engagement actions for the patient population based upon the health and wellness concerns at the individual patient best addressed at various levels in the system: for example, clinics and hospitals, counties and states, and ethnic groups. If some of the actions are important to health care professionals or policy makers but not identified as such by patients, additional marketing, promotion (eg, via media), or direct support may be warranted to increase patients' knowledge, which may lead to patients valuing the action (motivation) and learning to perform it (new practice or new behavior being developed). As for the implications for clinical institution implementation, integrating appropriate aspects of "The Patient Action Inventory for Self-Care" into the current electronic health record or patient personal health record system could increase the efficiency in data gathering and the timeliness in identifying and addressing the needs of individual patients and the populations being served. One possible institutional goal related to adopting "The Patient Action Inventory for Self-Care" in inpatient or outpatient settings is to improve population health and patient experience by supporting the needs important and desirable for patients. Another goal is to improve the efficiency of care transition and coordination across the care continuum, which could potentially lead to less financial burden on patients, clinical agencies, and the community as a whole.

As for future research, further testing of "The Patient Action Inventory for Self-Care" is needed to understand the dynamics of actions that are important to patients and the actions that patients are motivated to perform but lack the knowledge and confidence to accomplish. Future research may evaluate the association between the data collected by "The Patient Action Inventory for Self-Care" and concurrent measures, such as the Patient Activation Measure's four engagement stages. ${ }^{5}$ The reduced set version of the inventory presented here (35 action items) could be tested as a patient intervention in an outpatient setting or community to enable directed conversations for identifying desired needs for education or support to patients or their caregivers.

\section{Disclosure}

The authors report no conflicts of interest in this work.

\section{References}

1. Center for Advancing Health (CFAH). Engagement. Washington, DC: CFAH; 2016. Available from: http://www.cfah.org/engagement/. Accessed December 1, 2016.

2. Müllerová H, Landis SH, Aisanov Z, et al. Health behaviors and their correlates among participants in the Continuing to Confront COPD International Patient Survey. Int J Chron Obstruct Pulmon Dis. 2016;11: 881-890.

3. Pittman P, Forrest E. The changing roles of registered nurses in Pioneer Accountable Care Organizations. Nurs Outlook. 2015;63(5):554-565.

4. Center for Advancing Health (CFAH). Here to Stay: What Health Care Leaders Say About Patient Engagement. 2014. Available from: http://www. cfah.org/pdfs/here_to_stay_2014.pdf. Accessed December 12, 2016.

5. Hibbard JH, Mahoney ER, Stockard J, Tusler M. Development and testing of a short form of the patient activation measure. Health Serv Res. 2005;40(6 Pt 1):1918-1930.

6. Graffigna G, Barello S, Bonanomi A, Lozza E. Measuring patient engagement: development and psychometric properties of the Patient Health Engagement (PHE) Scale. Front Psychol. 2015;6:274. 
7. Center for Advancing Health (CFAH). CFAHEngagement Behavior Framework. Washington, DC: CFAH; 2010. Available from: http://www.cfah. org/engagement/research/engagement-behavior-framework and http:// www.cfah.org/file/CFAH_Engagement_Behavior_Framework_current. pdf. Accessed December 12, 2016.
8. Esposito EM, Rhodes CA, Besthoff CM, Bonuel N. Ambulatory care nurse-sensitive indicators series: patient engagement as a nurse-sensitive indicator in ambulatory care. Nurs Econ. 2016;34(6):303-306.

Patient Preference and Adherence

\section{Publish your work in this journal}

Patient Preference and Adherence is an international, peer-reviewed, open access journal that focuses on the growing importance of patient preference and adherence throughout the therapeutic continuum. Patient satisfaction, acceptability, quality of life, compliance, persistence and their role in developing new therapeutic modalities and compounds to optimize clinical outcomes for existing disease states are major areas of interest for the journal. This journal has been accepted for indexing on PubMed Central. The manuscript management system is completely online and includes a very quick and fair peer-review system, which is all easy to use. Visit http://www. dovepress.com/testimonials.php to read real quotes from published authors.

\footnotetext{
Submit your manuscript here: http://www.dovepress.com/patient-preference-and-adherence-journal
} 